Wayne State University

DigitalCommons@WayneState

English Faculty Research Publications

English

$1-1-2002$

\title{
Ghosts: Liberal Education and Negotiated Authority
}

Gwen Gorzelsky

Wayne State University, g.gorzelsky@wayne.edu

\section{Recommended Citation}

\section{Ghosts: Liberal Education and Negotiated Authority}

Gwen Gorzelsky

College English, Vol. 64, No. 3 (Jan., 2002), pp. 302-325

doi: $10.2307 / 3250736$

Available at: http://digitalcommons.wayne.edu/englishfrp/13

This Article is brought to you for free and open access by the English at DigitalCommons@WayneState. It has been accepted for inclusion in English Faculty Research Publications by an authorized administrator of DigitalCommons@WayneState. 


\title{
Ghosts: Liberal Education and Negotiated Authority
}

\author{
Gwen Gorzelsky \\ A basic error is not refuted. . . it can be altered only by changing the conditions of raw experience. \\ Perls, Hefferline, and Goodman, Gestalt Therapy
}

\section{Why Negotiate Professional Authority?}

W hat I want to know is why they have to take these courses," demanded Dan, who'd been brooding darkly across the Thanksgiving dinner table throughout the conversation.

I'd spent the afternoon helping intermittently with dinner preparations and listening to my sister-in-law Lee's story of her son's difficulties with his college writing teacher, problems worsened, she said, by his dislike for English. Hearing the account, I was almost relieved at being able to point out honestly that the instructor's behavior sounded at best unprofessional and at worst unethical. Now Dan, her husband, pushed me to address the larger issue rather than escaping into the specifics of his son's case.

"Right," Lee interjected, augmenting his question's force. "I mean if Jennifer wants to be a physical therapist," she said, referring to a niece, "why does she need English, or philosophy, or some of these other courses? 'They have nothing to do with what she wants to do. She'll never use them in her job. I mean, I can see math and biology. Those are important; they're directly related to what she wants to do. But why these others?"

I felt the question's force catalyze the energies of stray tense moments that had begun punctuating holiday dinners as nieces and nephews on my husband's side

Gwen Gorzelsky is Assistant Professor in the Composition Program, Department of English, Wayne State University. With a group of colleagues, she is developing graduate student internships in community literacy and in public vocations for the humanities. She is writing a book on how literate practices help to advance personal and social change. 
entered trade school or college. Confronted with its direct impact, I floundered. My husband's sisters and brothers are smart, informed working-class adults who, despite incidental struggles with unemployment and other financial strains, support their families, follow politics-and maintain a deep suspicion of higher education's institutional structure. Their lack of college education hasn't dulled their ability to comment shrewdly on the country's socioeconomic happenings or on the trappings of professional privilege. Dan now exercised that ability in a succinct materialist critique.

"You know what I think," he said, in the face of my failure to address the question. "I think it's just for the sake of the tuition dollars. The colleges charge an arm and a leg for one course and then stretch out the number of courses these kids have to take for no other good reason. It's just a scheme to make more tuition dollars."

Vertigo hit me as I confronted the double bind. On one hand, as the only person present to represent humanities instruction, I felt pressed to explain its importance. On the other hand, I empathized with my in-laws, who were scrimping and borrowing to pay the tuition dollars for kids who qualified for loans but not grants, despite the fact that their own wages and job security had rusted thin in western Pennsylvania's de-industrialization. And I knew that Lee and Dan understood clearly that college was potentially a golden key, a means for their two boys, in this cruel regional economy, to land jobs that would support a family, that wouldn't disappear in six months or a year. I struggled to explain the time-honored divide between college and trade school as one of vocational training versus the liberal education that traditionally launched professional life. "And people have assumed," I faltered, "that professional training requires knowing how to write, how to do the kind of thinking that a humanities education teaches." I backed out of the conversation slowly and carefully, a quick mental sweep of much of the scholarship and teaching I'd encountered in my years of grad school sharpening my anxieties about how to articulate just what that relation between professional training and a humanities education might be.

This opening vignette is formed from composites of various conversations and, occasionally, composites of characters. In contrast, the description of classroom interactions that begins section II is as accurate as I could make it by working from memory, without the aid of transcripts or field notes. Yet as the anecdote suggests, although others might well have negotiated the interchange more gracefully, my awkward silence in the face of my family's trenchant questions bespeaks a larger issue. The humanities in general education and English studies in particular face pressure, in the wake of poststructuralism, to address extra-academic audiencesparticularly working-class, working-poor, and lower-middle-class families-with a revised articulation of what a liberal arts education offers. If humanities instruction and a liberal education aren't to disappear from all but the most elite institutions of 
higher education, we need to help make visible to groups outside the academy, from parents to policymakers, how the seemingly esoteric work of English studies intersects materially with students' civic and professional lives.

This articulation requires us to negotiate with extra-academic audiences to craft a shared goal for liberal arts education, a goal in which academics and non-academics can invest themselves, a goal that furthers crucial priorities for each constituency. By revising liberal arts education to prepare graduates to negotiate professional authority in their fields, I believe English studies academics can undertake our side of this collaboration. I argue that negotiating our own professional authority can further key goals for each constituency. On the one hand, it can forward English studies' goals of encouraging critical thinking, cultural analysis, and preparation for democratic citizenship. On the other, it can forward public constituencies' goals of more equitable professional-lay interactions and more effective pre-professional training. By entering this kind of negotiation ourselves, we can make it part of what humanities instruction teaches. By teaching students to negotiate professional authority with lay people, we can help to construct the practices of a more democratic professional and civic life. Yet to undertake this negotiation, we must learn to work productively with the moments of professional-lay tension we encounter, both in the classroom and out.

\section{Professional Training and the Possibilities for Democracy}

The room's tense air crackled as I confronted my students' anger at the beginning of our third class meeting in a required freshman composition course. In the preceding session, I'd presented them with one student's anonymously reproduced in-class essay. We'd shuttled between the student's text and the assignment's quotation: "When a child first becomes conscious of himself, the way of life of his parents and companions will appear both natural and inevitable, but as he grows older and gains some knowledge, however incomplete, of other forms of existence, so he will begin to comprehend the peculiarity of his situation." ${ }^{1}$ Like most of the student essays, the one I'd picked to examine claims simply that author David Vincent depicts maturity as an inevitable result of growing up.

As I pushed students to grapple with the text's words and phrases, most, recognizing their own ideas in the anonymous student essay, insisted on the accuracy of its interpretation of Vincent's statement. Eventually Rox, who shaved the sides of her head and wore a long burnished blonde tail to complement her baggy hip-hop couture, recognized that close attention to the sentence's language could win her an entry into the conversation. Several students followed suit, and finally one used her classmates' translations of Vincent's corkscrew clauses to explain that he defines 
maturity as a result of recognizing one's difference from others, the peculiarity of one's particular formative circumstances.

But many other students seemed frustrated at being asked to wrestle with the nitty-gritty elements of sentences. That experience fueled their anger at having to clear the hoop of this inexplicably required course. In that moment, first-year composition seemed to stand for all humanities general education requirements. Students often resent these courses as distractions from the "real" work of their majors, and that resentment appeared to fuel my students' irritation.

Seething, they acknowledged that Vincent's definition of maturity indeed diverged from that of the student essay, but they shot back resentfully, "You made us change what we thought! You wouldn't let us just read it; we had to break it all up into little bits, and everything got twisted around."

I imagined that my students would still be angry the following Tuesday. They were. I announced that we would write about and discuss the work we'd done during the previous class. With handouts to remind them of our definitions, I asked students to write about what difference it made to use one definition or the other and about the difficulties, costs, and gains of doing the kind of work we'd undertaken.

When we opened discussion, I listened quietly to their ire at having an interpretation thrust upon them, an interpretation they apparently saw themselves as powerless to resist. That alone seemed to meliorate the tension. We then listed not only the difficulties and disadvantages of such in-class close reading but also what students might gain from it and, perhaps most importantly, how they might deal with its costs. Mollified, they suggested that individuals could return to their initial readings, that on appropriate occasions they could also read quickly, without this painstaking dissection. Yet people could apply the new tortuous method in situations that required it-situations like arcane college courses, they hinted. We had arrived at a fragile truce.

Students aren't the only skeptics regarding the value of required college-level English courses. These requirements are a hard sell, particularly to working-class families. The hazy connection between professional training and a humanities education makes such required courses difficult to justify, given their significant costs for such families. These costs take the form of postdegree debt, the loss of financial contribution or independence that college-age working-class students could otherwise offer their families, and the psychic costs of divided class loyalties. I see the experiences a liberal education offers (for example, learning to support an academic argument, reading Shakespeare and Kant, understanding the complexities of the French Revolution) as desirable in and for themselves. But I can't imagine trying to persuade my family that these experiences warrant binding their kids to a debt that can run to the tens of thousands of dollars and the strain of supporting young adults who would otherwise contribute to, or manage, their own support. Suggesting that 
people accrue such debt for the sake of cultural self-improvement implies that their own cultural activities and interests are fundamentally inadequate. It is an insult and often deeply resented as such. Thus as long as liberal arts educational experiences are decontextualized from students' future professional lives, their requirement remains a class-biased hoop whose cost and perceived irrelevance often make them an affront, as well as a barrier. This is particularly a working-class issue not only because middle-class families can typically manage college with less material strain but because cultural capital is often valued as such in middle-class homes: its acquisition doesn't produce generational tensions and divides in identity, as it often does for working-class students. These psychic costs are much discussed in composition theory, as in the paradigmatic books by Richard Rodriguez and Mike Rose. Yet this particularly working-class concern pushes me to grapple with the question of the relevance of liberal arts education for all students.

The question of relevance surfaces prominently at the strait where professional training and humanities education meet, the narrow passage whose history I tried to explain to my family. The passage is hazy, and its vapors mask the power of its converging tides. These form a whirlpool that's now siphoning resources from collegelevel English studies and engulfing the remainder of the humanities. The traditional role of liberal education, as a marker of class privilege, lives on as a ghost who guides the currents driving the whirlpool's downward flux.

The ghost recalls the days before experiments with open admissions, when a humanities education demonstrated one's class position, one's possession of that intangible stock-in-trade, cultural capital. Knowledge of the classics and the arts, the ability to write well, and a historical sensibility marked a person as cultured, presumably of "good background," and so as a candidate for professional employment. Gerald Graff and Michael Warner explain the historical roots of these assumptions about education in their introduction to The Origins of Literary Studies in America: A Documentary Anthology. For nineteenth-century American theorists of higher education, they note, "mere exposure to the products of literary genius was sufficient to arouse enthusiasm in the well-bred" (9). As a result, "appreciation of these [humanistic literary] traditions has been used to distinguish the elite from the vulgarity of the masses" (10). Graff makes the point more broadly about liberal education as a whole in Professing Literature: An Institutional History:

Since their beginnings in the seventeenth and eighteenth centuries, American colleges had been training schools for the professions.... Yet their idea of professional education scorned vocational concerns in favor of "liberal" studies, studies designed to form gentlemanly character rather than to train directly for a vocation. College presidents spoke of "gentle breeding" as a primary concern, and saw the study of literature through the classics as a form of acculturation for the "cultivated gentleman." ... [Their idea of leadership] assumed, as Edmund Wilson later wrote, that the 
country should be run by a "caste of trained 'college men' who were to preside over the arts and the professions." This assumed in turn that study of the classics was the best training for the professions, and that a cultured elite so trained would be able to control the twin excesses of grasping businessmen and unruly industrial proletarians. (20-21)

But that solid relation between "breeding" and liberal education has melted. With its dissolution, the figure guarding the strait of class mobility has vaporized into mist. Still, powered by his hand, the vortex is swallowing the postwar plans that made humanities education more available to groups previously excluded. If those possibilities disappear, if such education is again available virtually only to the welloff, the ghost will re-embody himself. Then the relation between breeding and cultural capital will resolidify.

Both an educational utilitarianism and the current form of professionalization within English studies drive this vortex. My students' and my family's suspicion of humanities courses, from freshman composition to literature and philosophy to art history, stems from a vocational or trade school understanding of education's meaning and uses. But that utilitarianism is also fueled by political and university administrations. Legislators seek to cut public dollars spent on education. Colleges and universities seek to maximize tuition revenues and minimize operating costs. Together, these currents are inundating the humanities. Both mainstream media and the professional journals document this trend. ${ }^{2}$ Elizabeth Langland, English professor and associate dean for faculty affairs at the University of Florida, quotes J. Hillis Miller's assessment of the current threat to humanities education: "It will be hard to keep the humanities from becoming vestigial, from becoming no more than an assembly of programs that teach the communication skills needed by educated technocrats in the service of transnational corporations" (qtd. in Langland 15). Professors and administrators alike explain that introducing corporate operational models into higher education has intensified this utilitarianism. The market ideology driving our culture powers the political forces slicing higher-education funds. My family's and students' utilitarian approach to education encourages these forces as well. Thus working-class utilitarianism may ironically help to resolidify working-class students' exclusion from higher education. Yet utilitarianism also has broader effects. Its debilitating consequences for civic life, for democracy as a potential form of government, have been demonstrated by the German philosopher Jürgen Habermas. The humanities, it seems, are the exquisitely precious decorations of a ghostly-or perhaps only an imagined-way of life.

Habermas paints a society whose nascent democratic potential has been absorbed by the market. In his portrayal, postmodern, post-industrial society pushes individuals to define their identities not as participating citizens but as professionals, clients, and consumers. It teaches us to view our authority to make judgments as 
constricted to a narrowly defined vocational sphere. At its prompting, we learn to invest our energy and resources in ever more encompassing consumption and professionalism. Habermas explores how public dialogue and active citizenship, the heart of a living democracy (or our dream of one) have failed-strained by consumerism, corporate professionalization, and the welfare state. Public discourse, he argues, is a casualty of the market because a narrow professionalism privileges disciplinarily grounded authority. Thus it subverts the social possibilities for more democratically grounded authority. Habermas, therefore, seeks to rescue this democratically grounded authority by working to increase people's investment in public discourse and to decrease that in professionalizing.

Although his analysis powerfully describes democracy's current state, I use it to rethink, rather than circumvent, professionalism. Further, with others, I question portions of Habermas's historical explanations and conception of language. ${ }^{3}$ I see the historical and present existence of democratic practices as more nebulous than he does. Thus, rather than first seeking to revitalize a public discourse whose inclusiveness is so tenuous, I seek to shape more democratic professional practices. Unlike Habermas, I see professionalism not as a hindrance but as a potential tool in the struggle to initiate more democratic relations. Because professionalism occurs at the level of daily practices and interactions, it structures our identities and relations with one another. Because relationships with professionals touch the lives of nearly all first-world inhabitants, the professional ethos directly impacts more Americans than does public discourse. Both features make professionalism a potentially productive site for initiating more democratic practices. Such a revision would open a narrowly defined disciplinary authority to negotiation with the people (students, patients, clients) whom professionals both serve and regulate. This change would shift authority from disciplinary expertise to the negotiation of decisions by everyone involved, professional and lay.

If I'd had the presence of mind, I could have used Habermas's critique of democracy to suggest to Lee and Dan that one of the key problems with professional training is that it teaches professionals (like doctors, social workers, and local government administrators) to see themselves as authorities and their patients or clients as subject to their direction. I've listened to many working-class adults, including my family, complain legitimately about professionals' high-handed manners. Thus I think Lee and Dan might agree that training professionals to see authority as a topdown channel, rather than as a joint negotiation, not only offends clients' dignity but also infringes on their rights to participate in decisions that affect their lives. That said, I could have argued that the goal of a liberal education has traditionally been to train professionals to understand and respect people of different ethnic, socioeconomic, religious, or other background. But, of course, I would have had to acknowledge that liberal education to date has come only a short way toward ac- 
complishing this end, partly because it hasn't articulated its goals concretely with pre-professional training.

This failure springs partly from an over-emphasis on rationality, to the exclusion of affect, the emotional energy expressed (often nonverbally) in interpersonal exchanges. Reshaping professionalism toward a more democratic ethos demands more than the rationalistic communication Habermas posits as the medium of public discourse. As Young and others have shown, Habermas fails to acknowledge and address the ways in which affect shapes communicative exchanges, including both professional and public interactions. Addressing affect's role is crucial in any effort to foster democratic practices and, more specifically, in any effort to foster more democratic negotiations of professional authority. Composition theorists have emphasized that the affective relations between students and teachers fundamentally structure learning and student investment. For instance, Shor repeatedly emphasizes emotion's significance in a critical pedagogy that negotiates teacher-student authority (see also Ball and Lardner). By stressing its role in this democratic endeavor, Shor's work implies that to foster a more democratic, negotiated professionalism, we must work to increase awareness of such affective dynamics in professional interactions.

\section{Democratizing Professional Authority}

So I ask myself, what could a reshaped humanities education, given its spectral Janus function as the gatekeeper of class privilege, as barrier or safe passage, possibly offer to an effort to rescue-or animate-democracy from the vortex of capital? How can we revise humanities education to help us, with students, to enact and teach a more democratic form of professionalism? How can we use its concern with the varied dimensions of human experience to harness attention to affective interactions with attention to power and authority?

For instance, given my students' view of our work with Vincent as an esoteric imposition of my authority, how were they positioned to use such work in their future professional lives? Given our negotiations between it and their own investments, what did they learn about the possibilities for democratizing disciplinary authority and professional expertise? That is, what kinds of mastery did they initiate through it?

To begin an answer, I'll trace the revisions of one student writer to extend Shor's theory of critical pedagogy. Contending that traditional education has proven itself unequal to its stated goal of redressing social inequities, Shor argues that this inability stems from its inherently authoritarian, anti-democratic structures. While emphasizing that authority does not disappear in critical pedagogy, he shows how this approach simultaneously increases students' investment and engagement in learn- 
ing and in democratic, negotiatory processes. Explaining that in traditional education students experience authoritarian relations while bearing that their society is democratic, Shor argues that because we learn what we experience, such contradictions teach us to enact hierarchical, rather than negotiated, relations with one another. "Years of traditional socialization cannot be overcome at once," he concludes. "Habits of democratic dialogue can be learned only through extended experience in counterstructures" (260).

His critical pedagogy offers such a counterstructure, a negotiating space where teachers address students' affective, as well as intellectual, concerns and use crossdisciplinary instruction to study problems based in students' experience. To produce this space, Shor encourages teachers to transform our pedagogical practices, to change the habits developed by watching our own teachers and ingrained by years of repetition. Suggesting research into the strengths and liabilities both teachers and students bring to instruction, Shor advocates transforming the interactional habits that enact authoritarian relations. "A mutual transformation of academic and community cultures is necessary," he claims, urging student and teacher changes. Neither academic nor lay knowledge can single-handedly generate social change, he concludes (255). Shor's suggestions that we address affective, as well as intellectual, concerns and that we revise our own professional exercise of authority have helped me rethink my teaching. Using his suggestions, I've revisited texts that one student, Rox, wrote for the freshman course depicted above.

In theorizing a means to democratize disciplinary authority and professional expertise, I extend Shor's model of critical pedagogy. Specifically, I explore how affect and affective dynamics figure centrally in fostering students' active engagement with disciplinary knowledge. Further, I analyze how these dynamics play a crucial role in the kind of teacher transformation Shor advocates. By pursuing the question of affect's role, I take up a direction Shor stresses but develops minimally. His discussions of specific classroom interactions center primarily on the cognitive dimensions of instructional dynamics (he emphasizes rationalist modes such as debate, for example, in his specific descriptions of how critical pedagogy encourages students to consider their own ideological positions [see 64-65]). I examine the interweave between emotion and cognition. Similarly, by rethinking a specific facet of my own teaching practice, I extend Shor's notion of critical pedagogy into an area he emphasizes but does not probe.

I begin by reading the texts of a student writer whose work hints at how the existing capacity for critique that many students bring to college could be used to develop a revised liberal arts education. Rox's work reveals glimpses of the skills we and students might gain by making disciplinary practices negotiable rather than authoritative. By the term's conclusion, she'd used the methods of two course texts, Lynn Emanuel's The Dig and Carolyn Steedman's Landscape for a Good Woman, to 
pursue her own intellectual ends. Specifically, she'd combined an imitation of Emanuel's poetic form with a Steedmanesque analysis to craft a means of representing what it meant to live with her father after her parents' divorce. "Escape," fifth in a series of seven poems, follows the depiction of a screaming mother and embodies Rox's unfolding understanding of how to use metaphor:

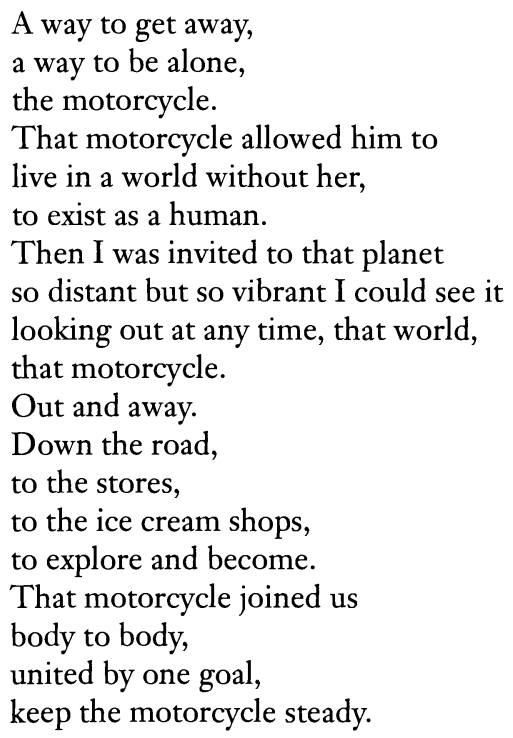

Here, Rox as writer reworks the clichéd motorcycle to represent her particular circumstances and, in doing so, reworks the figure of the departing father and the moment of familial dissolution. In contrast to fatherly escape as abandonmentmotorcycle as means to freedom from family commitments-Rox's poems depict that departure as the door to father-daughter connection. "Escape," in particular, makes it a moment of construction rather than of disintegration. Implicitly, the group of poems portrays a family romance that challenges both Freud's version and the talk shows' diagnoses of divorce: Rox's character is drawn to that of her father not because he represents power but because he represents nurturing and her escape. In effect, Rox's poem twists a clichéd metaphor to refract our culturally prefabricated image of the family and its possible relations through the lens of her experience.

Rox accomplishes this refraction because her poems use the structure of the course's assignments-of her initial English studies instruction-to develop the incipient critique she brought with her into the course. Thus in addition to Shor's call for teachers to explore and use students' language in the classroom, Rox's work suggests the importance of teachers' efforts to explore and use the nascent critiques students bring to their classes. Further, though, Rox refracts our pictures of the family by linking her investments with required course work. Specifically, she integrates 
her emotional experience into an academic writing assignment. Because she succeeds in negotiating her own perspective and investments with the authorized disciplinary practices she is learning, Rox both generates academically successful work and crafts for herself a relatively equitable relationship with disciplinary authority.

As one reader of this piece suggested, my family, like many parents and legislators, might see Rox's poem as esoteric, irrelevant to her long-term goals, particularly to her professional training. Yet in writing the poem, Rox built the foundation for her later work. Because she articulated her experience as evidence in the poem, Rox could later use that experience to critique existing psychological research on families.

She began that project in response to an assignment asking her to incorporate Steedman's writerly methods into her paper. Rox proposed some library research into the psychological literature on children and divorce. Her goal was to take up Steedman's practice of revising common "interpretative devices," which, in Landscape, range from fairy tales to psychoanalytic case studies. Rox's analysis of the divorce literature uses her depictions of her own experience to begin pushing on that body of knowledge in much the way that Steedman critiques and revises Freud:

Even during my research for this paper, I found an incredible amount of information about the [e]ffects of the father on children who live with their mother and very little about the relationship of children and fathers when the children live with the father. As I was finding this, I also discovered that I was not surprised, I have encountered this for years and even fought it myself during the divorce, so why should this be any different[?]

By not considering this end, researchers are leaving a gaping hole in the information of divorce. ... This "fact" that is taken for granted in our society makes it more difficult on divorced children. When it becomes their choice to decide, even they find themselves expecting to live with their mother. Suddenly, they are making excuses for why they are living with their father; it should be accepted.

Rox's brief analysis of the psychology literature on children and divorce exposes the intellectual violence of finding her experience erased by both lay and disciplinary knowledges. It explores this distortion's impact on her life, illustrating vividly how the representations produced in such writing pressure the children and adults grappling with divorce. Here, Rox uses the disciplinary form of critique promoted by English studies to develop the incipient critique she'd brought to the course. Because she has found a way to link her own emotional investments with the work this form requires, she recognizes the form as useful and grasps it for her own purposes. Rox inhabits and reshapes the form for her ends by infusing it with her own affective energy.

Her efforts thus extend Shor's call for experiential learning fostered through discussion and group work. Shor emphasizes experiential change as an essential means 
of teaching students bow to engage in intellectual and critical exchanges. Yet he, like Habermas, implies that ideological change is driven by argument-based, rationalist discourse rather than by affective dynamics and experiential shifts. Rox's work suggests the opposite: by harnessing her poems' depiction of emotional experience to generate an academic critique, she transforms her own experience. Her work suggests that such changes ground ideological revision. That is, the very act of producing her critique changes Rox's power relations with the authorities she challenges (teachers, social workers, psychologists). This change enables Rox both to show and question the limits of such authorities' empathy and disciplinary mastery. She does so by articulating an alternate, previously inaudible perspective, one that draws on her emotional experience. It uses both affective and rationalist elements to encourage readers to shift their own ideologies regarding their relations to such authorities.

Thus Rox's work shows why a revised professional preparation is necessary and why it's significant not only to academics but to public constituencies as well, working-class and otherwise: professional knowledge, as it is currently deployed, prompts professionals to enact an authoritarian, hierarchical model. Our cultural presumption that it is possible to objectively exercise professional knowledge and judgment intensifies the problem. Clearly, professionals have knowledge and experience that the layperson does not possess. Yet this expertise does not mandate a hierarchical authority.

The complexities of professional-lay relationships emerge pointedly in two paired ethnographic essays that explore the politics of breast cancer treatment decisions. In "Thrown Overboard: The Human Costs of Healthcare Rationing," medical sociologist Aliza Kolker documents her own experience with breast cancer and her losing fight to get her Blue Cross/Blue Shield managed care plan to pay for the autologous bone marrow transplant (ABMT) her oncologist recommends. When Kolker and her husband decide to pay for the costly invasive procedure themselves, she receives less than standard treatment in the hospital and encounters resistance from Blue Cross /Blue Shield regarding payment for all treatment of her cancer.

Yet in a sister piece, "The Lifeboat Is Fraught: Reflections on 'Thrown Overboard," R. Ruth Linden questions the use of expensive, toxic procedures like ABMT (which requires follow-up with intensive chemotherapy treatments). Linden, a philosopher of science, urges patients to engage with unresolved medical questions, to recognize that medical authority isn't monolithic, and to challenge it. "Experts-in this case medical oncologists-can and do disagree, as a matter of course, about which therapy is likely to be most effective for a particular patient" (161). Citing conflicting views on ABMT's status (proven or experimental), Linden holds that for-profit health care exploits a desperate patient market when it promotes treatments like ABMT for patients whose cancer has metastasized. Citing successful AIDS and breast cancer activists' efforts, she argues that patients must lobby pharmaceutical 
manufacturers to develop innovative noncytotoxic therapies, to provide access to experimental trials of such therapies, and to conduct continuation protocols where appropriate.

As these essays demonstrate, complex and conflicting interests pervade this issue, making it impossible for experts alone (even experts from across several disciplines) to ethically impose a decision. No expert is outside the web of disciplinary, professional, and self-interest. Thus developing an ethical approach to the problem requires a dialogue among various professionals and lay people. Despite the difficulty of defining professionals' role in such a dialogue, an ethical decision-making process requires a professional-lay collaboration rather than an imposed professional judgment.

Of course, now the process usually works hierarchically, so that professionals presume their [our] judgments hold sway. They-we-often infantilize people outside our disciplines. My family, for instance, intermittently complain of high-handed treatment by doctors, social workers, and civil functionaries who have dismissed or disrespected their concerns and expertise, often out of failure to recognize how cultural and class differences can produce divergent pictures of a situation.

Such patterns of professional interaction have been documented beyond anecdote. For example, Ellen Barton's conversation analysis of medical encounters demonstrates that medical professionals in such encounters "reproduce power and dominance in fairly predictable ways" (430). While asymmetries between medical professionals and patients/families span all classes, such professionals' interactional moves are "collaboratively negotiated with family members high in [cultural] capital" but "adversarially imposed on Medicaid families without much cultural capital" (431). Barton concludes that "[i]t is those without cultural capital who seem to be systematically constructed into adversarial relationships throughout the encounter" (431). The problem of authoritarian professional interactions thus spans classes, but working-class participants tend to experience it most sharply.

Given the typically inequitable, disempowering lay experience of professional interactions, it seems crucial to develop practices for making such encounters negotiated and democratic. A revised liberal arts education could more effectively prepare people to become professionals who listen, who understand and respect such differences, and who negotiate with, rather than direct, their lay partners. Certainly this goal dovetails with some of liberal education's traditional ends, such as expanding students' sensibilities. But it dovetails yet more closely with poststructuralist arguments for recognizing and understanding fundamental class, gender, and cultural differences and for attending to power dynamics. As a goal, it provides a means for teachers to pursue the democratic practices and relationships sought by critical pedagogy. Perhaps most importantly, it is a goal many working-class families share, whether implicitly or explicitly. It thus lays the foundation for an ethical, socially 
viable argument for requiring a reshaped liberal arts curriculum in pre-professional education.

But to revise liberal arts education so that it teaches people to democratically negotiate professional authority, we must revise our own current form of professionalization, which promotes a narrow expertise, conventional notions of mastery, and hierarchical relations with others. According to David Shumway, this form of professionalization has made English studies more socially marginal by prompting most practitioners to withdraw substantively from lay conversations and, by extension, from undergraduate education. Shumway faults the academic star system for weakening public confidence in the profession and calls for a more collective professional ethos (86). In particular, he blames academics' loss of voice in literary journalism on a disciplinarity that "requires that practitioners write for one another rather than for the public at large" (98). He concludes that by locating disciplinary authority in academic stardom, we have "reduced the legitimacy of the discipline's discourse in the culture at large" (98). We've abandoned writerly efforts to negotiate with a lay public to instead assert the primacy of professionalized knowledge. The resulting loss of public confidence generates lay people's skepticism about the value of humanities education. Eventually, it undermines humanities requirements and funding.

Similarly, John Guillory analyzes how the narrow, hierarchical professionalism we now enact has generated the long-standing Ph.D. glut. The impetus to teach graduate students as opposed to undergraduate, he notes, is "the most symptomatic professional desire one can harbor today." The implicit goal involves "reproducing [in graduate students] the same professional desire that emanated from their teachers" (97-98). We don't prepare Ph.D. students for a broader range of potential careers outside research institutions-and so work to make their training relevant to constituencies outside our discipline. Instead, we focus on ever-narrowing bandwidths of subdisciplinary expertise. Rather than articulating our work to lay audiences, we produce interested readers by multiplying graduate programs. But widespread gratification of the desire to teach graduate students demands an everexpanding graduate student body. Thus, Guillory concludes, "the desire itself is phantasmatic" (98). That is, our professionalization now pursues a ghostly end.

This approach levies heavy intellectual tolls. Through it, we've manufactured a hermetic professional discourse whose important theoretical sophistication hamstrings our potential to participate in the variety of more public conversations we might productively enter. Thus we vest our professionalized discourses with the same epistemological authority we critique. That is, we solidify - rather than loosenthe relation between disciplinary mastery and sociopolitical power, although that relation is often precisely what we critique. By insisting on a deep, narrow subfield knowledge as the prerequisite for authorized participation in academic discourse, 
we enact the very model of disciplinary mastery (of professional-lay relations) that poststructuralist theorists critique (see, for example, Foucault; Said; and Spivak). Such pressure discourages crossing subfields, much less disciplines. By rooting our work in narrow subdisciplinary mastery, we move away from potential connections with readers outside our disciplines, let alone with lay audiences outside the academy. Through this exercise of professional authority, or disciplinary mastery, we withdraw from vigorous engagement with our lay constituencies (students, parents, legislators). We hamstring our potential to articulate our professionally informed perspectives and concerns to these constituencies.

In practical terms, this narrow(ing) professionalism threatens to swallow itself. By decreasing the humanities' perceived cultural relevance, our inadequate articulation intensifies the trend toward a strictly professional-technical training. Thus our narrow, hierarchical professionalism permeates humanities scholarship and instruction and, ironically, threatens to eliminate that instruction for all but the privileged few. The tension between writing primarily to other professionals and writing to a broader audience (of both students and general readers) is not new. Graff and Warner document how this tension helped to constitute English studies as a discipline. But as Guillory and Shumway demonstrate, in the past thirty years the tension has deepened to produce a new kind of crisis in most practitioners' working conditions and in the culturally perceived relevance of the field.

This intensification has had serious consequences for teaching as well. In pedagogical terms, this approach relies on inspiring students' passion for a particular subfield without considering how to help them construct useful intersections between that passion and either their realistic employment possibilities or future professional lives, whether they are graduate or undergraduate students. This approach raises Guillory's phantasmatic-and symptomatic - professional desire to teach students committed to one's subfield for its own sake. Thus it speeds the vortex doubly. First, it leads us away from vigorous investment in the project of teaching undergraduate courses, particularly lower-division general education courses. Second, in doing so, it leads us to ignore the kind of financial concern raised by my family, to marginalize lay (particularly working-class) constituencies' material and psychic experiences of education. Those tendencies exacerbate the apparent irrelevance of English studies to lay constituents and undermine general education English requirements. To make English studies' relevance clear to these groups, we need to articulate our disciplinary concerns with their lay concerns. Just by doing so, we'll begin to revise our exercise of professional authority.

\section{Teaching Negotiation}

Pursuing this revision means redesigning our scholarship, our curriculum, and our pedagogy. Such work must be gradual, enacted as a series of cyclic negotiations 
among various constituencies, from English studies' own subdisciplines and varied institutional contexts to university administrators to students, parents, and interested lay audiences. It's especially crucial because our current professionalization of scholarship subordinates and silences the majority of the profession's practitioners, particularly those who engage most extensively with students. Using the same high theory that critiques disciplinarity, it slices "untheorized" pieces from the respected venues that publish professionally authorized work. Thus it forecloses other kinds of intellectual projects, projects rooted in people's work at community and liberal arts colleges, for instance, and in their strategies for articulating the concerns of the discipline to their students and communities. In short, our current form of professionalization discourages the kind of scholarship we most need.

I suggest we root scholarly work in the ground between disciplinary and extradisciplinary discourses and practices. Thus we'll invite practitioners from varied institutions to participate, and we'll begin to negotiate with lay audiences. I initiate this effort by reading Rox's work to theorize a more democratic disciplinary authority and to explore how I, as a teacher, might more productively have addressed my students' sense of intellectual violence. Thus I show how a revised English studies scholarship can prompt revisions of pedagogy and, eventually, of curricula.

Reading Rox's work through the lenses of my own and another discipline enabled me to see and rework the limits of my empathy. I believe a renewed liberal arts education can teach this process of recognizing and revising the limits of empathy. But the process requires a professional-lay relationship where authority is negotiated. Thus teaching it demands that we as practitioners revise our exercise of professional authority. Through that revision, we can model more democratic professional-lay relations with and for students. This change could fundamentally shift the nature of students' (especially working-class students') experience of higher education. That shift would till the ground for a broader revision of professional-lay relations.

Rox's work illustrates a student's struggle with the intellectual violence that college courses trigger in students' experience. One form of this violence seems inevitable to me. Encounters with disciplinary knowledge demand that students supplement the lenses they've brought into college by gazing through the uncomfortable eyepiece of a disciplinary microscope that renders some familiar crumblike a sentence-into a world in itself. While the microscope's lens reveals only one facet of the world, as any discipline illuminates a particular aspect of human existence, students begin to grasp that their own eyes, whose lenses are inevitably shaped by their bearers' subjective experiences and social positions, similarly blur some facets of the world. They begin to experience for themselves Vincent's maturation, to recognize the narrow particularity of their own vision and formative circumstances. This recognition pushes students-all of us-to experience three things: the inevitable limits of our own vision, the chance to refract our pictures through others' 
lenses, and the inescapable realization that we can't ethically generalize and proscribe from our personal experiences or from a given discipline's knowledge. As Shor notes, such experiences can provoke anxiety (259).

Through them, we recognize a fundamental ethical dilemma of human existence and interaction: the need to negotiate among sometimes radically disjointed pictures of an experience. We recognize the limits of empathy, as a response inevitably shaped by our particular day-to-day discourses and experiences, by the landscapes of our own backgrounds. Traditional liberal education addressed this human limitation by treating it as a result of our provincialism, which it sought to cure by exposing us to a broader, more cosmopolitan world of art, literature, and philosophy. Through this exposure, it attempted to expand "well-bred" individuals' inherent empathic capabilities. A revised liberal arts education would value empathy and encourage us to understand and respect empathy's limits. It would value "vulgar," as well as well-bred, sensibilities. Such understanding and respect take root in recognition of humans' fundamental differences as the basis for negotiating conflicting experiences and representations of reality.

Rox's revisions grapple productively with this form of intellectual violence. Through them, she uses it to grow, rather than succumbing to it or rejecting it. However, another common form of intellectual violence is named in my students' charge: "You made us change what we think." Their phrasing evokes Foucault's analysis of how disciplines de-authorize lay perceptions and knowledges so that lay people find themselves objectified and sometimes pathologized (see, for example, The History of Sexuality). This form of violence grows from hierarchical professionallay interactions, from conventional notions of mastery. It is more modifiable than the violence of encountering incommensurable worldviews. But the two forms of violence often blur together in classroom interactions. I think students sometimes resist the productive conflict because it has blurred with authoritarian approaches to disciplinary mastery. Rox's generative use of incommensurable knowledges has prompted me to re-see how I enacted and, to some extent, revised this authoritarian approach. Further, it has helped me to develop a richer view of my students' experience of the conflicted class period and to imagine how I might construct a more negotiated exercise of professional authority.

Rox grapples productively with the first type of intellectual violence precisely because she finds ways to appropriate disciplinary authority to oppose the second type. Working across genres (poetry and critique) and across disciplines (English and psychology) enables Rox to develop her incipient critique of authorized discourses. Thus she negotiates disciplinary authority rather than either subordinating herself to or rejecting it. She integrates new content and methods from these disciplines with her experience and affective investments to do so. Her mother, Rox explains, "is not the only one that I have encountered to assume that I should or 
would be living with my mother. I found that teachers are very often surprised when they find that a child lives with his father." To support her negotiation with teachers' authority, Rox analyzes the psychology literature on children and divorce. "Fathers have been accepted as the parent who has the harder time relating to the child," she explains, before going on to cite a specific text. "The relationships that improve between father and child, according to Wallerstein and Kelly, are 'eroticized.' These children seem to acquire 'erotic feelings' for the father because the father is no longer the one who rules and the relationship is free to evolve without restrictions. However," Rox concludes, "Wallerstein and Kelly never consider the child who chose to live with their father." In this critique, produced through her use of English studies' disciplinary practices, Rox negotiates an authority for her own perspectives and investments in relation to psychology's disciplinary authority.

But Rox similarly shifted her relationship with English studies' disciplinary authority as well by claiming writerly authority over her text's development. Although I suggested she analyze the connection between the poems and her critique, Rox decided, after thought and discussion, to juxtapose these textual elements without such analysis. Her decision has writerly integrity. It takes shape from the affective investment that enabled her work in the first place. By using and challenging two disciplines' materials and practices in this series of assignments, Rox negotiates a generative, relatively equal relationship between disciplinary expertise and her own experiential knowledge. She recognizes the diffractions in the psychology literature and in my comments' representation, and she uses disciplinary practices to negotiate those representations with her own. By experiencing, rather than only analyzing, the limits of such representations, she begins to address fruitfully the limits of disciplinary mastery. In short, Rox begins to establish disciplinary, and writerly, authority. But her process of developing this authority shifts the nature of that authority from hierarchical to negotiated.

By integrating disciplinary training with her investments, Rox's work suggests how students and lay people can negotiate their perceptions and priorities with disciplinary knowledge and professional authority. It evokes a revised liberal education that would help students to integrate these knowledges. This renewed education would teach students to recognize how any representation both diffracts and embodies people's experiences and psychic investments. In particular, it would help all of us to learn how to negotiate these diffractions and investments. Thus it could help us to recognize-and rework--the limits of our own empathy. Given students' goals, this revised liberal education would still help students develop the expertise they need to enter positions of professional authority. Yet in teaching students to negotiate between lay and disciplinary knowledges and among conflicting knowledges, it would prepare them to work collaboratively, rather than hierarchically, with their own lay constituents. 
To develop this education, we need to integrate our focus on texts, skills, and content knowledge with a focus on what people, individually and collectively, $d o$ with those texts, skills, and knowledges. We need to show students how using these tools can help them to develop skills for negotiating cultural difference, skills that will make them better professional practitioners. We can't accomplish this work simply by teaching humanities texts and skills (such as close reading, historical research, or cultural analysis) because negotiated, democratic practices don't lie prefabricated in such texts or skills. Rather, we produce them through the interactions between text and reader, between reader and writer, between reader and reader. To generate and model such interactions, we must learn to read students' work and classroom interactions with the intellectual generosity and depth illustrated by compositionists such as Kurt Spellmeyer. Such readings can help us to use rhetori$\mathrm{cal}$, aesthetic, and critical analyses to understand students' psychic experiences and investments and thus their class and cultural differences, their resistances. To comprehend such differences, we must devise intellectual projects that help us to recognize and explore the affective dynamics in our professional interactions with students. Through this work, we can learn how to enact listening, respect, and negotiation of authority in our relations with students.

Lu and Horner's "The Problematic of Experience: Redefining Critical Work in Ethnography and Pedagogy" provides crucial tools for this project. It supports the teacher change Shor advocates by offering a method to recognize and transform pedagogical habits that enact authoritarian teacher-student relationships. Lu and Horner show how we can use critical ethnography to problematize not only the student's experience, as in most critical pedagogy, but the teacher's as well. Thus, they argue, we can creatively use two tensions: research versus teaching and respecting students' existing experience versus seeking to change that experience. We can promote our collaborative change with students rather than our singular change of students.

I take up Lu and Horner's approach by analyzing the social and emotional dynamics in specific classroom interactions (and related texts) to explore uses of authority, negotiation, and the flow of power. The dynamics of such mundane interactions are key to fostering democratic practices. Examining them to problematize instructor experience can help us to revise our exercise of professional authority. Through such scrutiny, we can develop ways to creatively use the tensions inherent in teaching and research. Clearly this approach alone won't produce sweeping social change. But it does offer a substantive, perhaps even decisive, way for liberal arts teachers and scholars to foster such change. And as Shor demonstrates, such educational revisions can support broader social movements (see especially 19699). Rox's critique of the psychology literature prompted me to ask how I might examine my own exercise of professional authority. By urging me to look for the 
inevitable distortions produced by my own discipline's lenses, Rox's work suggested I return to Vincent. In doing so, I was moved to examine how the particularity of my own formative circumstances (my professional training) constituted "the peculiarity of [my] situation" (my relationship with my students).

This examination proved fruitful. I realized I'd blinded myself to the differences between my position and theirs and so to the possible social, emotional, and intellectual implications of my pedagogical moves. To begin, I speculated that my students may, in part, have resisted the unfolding reading of Vincent's definition of maturity not only because it contradicted their initial readings but because it threatened their identities. Nearly all are western Pennsylvania natives, and many commuted to university from small, fairly homogeneous communities. By insisting we work out a passage that suggested juxtaposing self with difference as the criterion for maturity, I may have implied that their families had not attained maturity and so infantilized and insulted students' communities. But as I didn't pursue the question at the time, I just don't know how students experienced my insistence that we work out the text's implications.

The point is that I could have explored that experience with them in dialogue, if I'd only recognized the need to do so. No dialogue would have brought us to the unmediated truth of the interaction. But as Shor suggests, I could have worked with students to explore their resistance to this reading and to validate the grounds of that resistance. Such validation is key to negotiating authority and moving beyond the pressure-resistance deadlock. That is, we can help students learn to negotiate professional authority by using humanities texts to negotiate with our key constituents-particularly our students. To do so, we must use our disciplinary knowledge and practices to appreciate the social, emotional, and intellectual dynamics of classroom interactions. Thus we can grasp the limits of our own empathy and rework those limits. For me, this meant using Vincent's text to speculate on why students may have resisted the work I'd initiated. Ideally I'd have used this speculation to explore this resistance with students. Thus I would have revised or extended my understanding of their perceptions.

By continually testing our guesses in interactions with students, we can model the ongoing efforts at understanding needed to work collaboratively with others. I haltingly initiated this process in my class and have taken it up retrospectively in this paper. For instance, I began this move in asking my students to discuss the uses and drawbacks of close reading, but I stopped short of exploring with them when and why it may sometimes be intellectually productive to resist such disciplinary practices.

In my current research, I'm exploring how to use my disciplinary knowledge and practices to more effectively negotiate authority. Specifically, I'm integrating my disciplinary expertise with efforts to understand and respect students' psychic investments and social-emotional dynamics so we can better work with cultural and 
class differences. To do so, I'm filtering my training in composition and social and literary theory through the lenses of another discipline, namely Gestalt psychology. For instance, I'm reading theories of social construction through the Gestalt notion of phenomenological listening (see Zinker, especially 93-96). Thus I'm developing an understanding of metaphor as not only a literary device but also as a form that structures our relationships and social dynamics. ${ }^{4}$ By re-examining students' language during the tense class session, I've come to hear deeply embedded metaphors for an authoritarian, paternalistic relation ("You made us change ..."; "You wouldn't let us ..."; We had to ..."). As I hear these metaphors through the filters of Rox's, Vincent's, and Gestalt psychology's texts, I think it likely that my students experienced our contested class period as fundamentally disrespectful, even demeaning. Without consciously intending to do so, I staged a heavy-handed demonstration of students' misreading of Vincent. How could they interpret this move other than as an illustration that they were wrong, inadequate to the task of intellectual work? They probably experienced the session as an infantilizing, hierarchical enactment of professional authority.

Yet despite my profound discomfort in this realization, I see it as a small but crucial moment of intellectual and teacherly growth. Through it, I am recognizing and reworking the existing limits of my own empathy. Had I engaged in dialogue with students about their psychic experience of the interaction, I would have more effectively negotiated authority with them. I would also have modeled for them one possible approach to democratizing the authority dynamic in professional-lay relationships.

Undertaking cross-disciplinary scholarship that deliberately combines research methods is crucial to fostering such democratization. First, it pushes me to work regularly at the boundaries of my disciplinary expertise, to engage substantively with unfamiliar material and approaches, where I have no mastery. It forces me to negotiate my professional expertise with authorized material outside my ken. In doing it, I integrate a familiar set of discourses and practices with an unfamiliar set. Second, this approach helps me to integrate my disciplinary training and questions with a process of learning about my students. For instance, it prompts me to consider researching students' metaphors for their relations with texts and teachers to learn how I could support students in the kind of negotiation Rox accomplished primarily on her own. It enables me to combine attention to metaphor with attention to interactional dynamics and so to use students' feedback to problematize my teacherly experience.

The move to cross disciplines and combine research modes must figure in any effort to redefine liberal arts education. Paul Kameen demonstrates its significance in his evaluation of the current state of higher education: "The larger form of the question-'What is the pedagogical mission of the American university at the end of 
the 20th century?'-is impossible to answer from any one disciplinary site. It requires instead a larger-scale inter-disciplinary dialogue" (183). Composition, he argues, has particular potential to further such dialogue for two reasons. First, it already engages in an intense, foregrounded discussion of epistemology in its struggle over research methods, from quantitative to qualitative to critical-analytic. Second, it has a history of linking disciplinary and scholarly questions to issues of pedagogy, curriculum, and students' experiences and concerns.

In such cross-methodological, cross-disciplinary scholarship, expertise derives not from traditional notions of mastery but from a fundamental engagement with the limits of mastery (and the limits of empathy) in any given discipline. This approach can help us to develop the skills for negotiating our professional concerns with our various constituents' concerns. For instance, I ask students to engage productively - though not unquestioningly — with the practical, theoretical, and ethical issues of representation raised by the intellectual left. At the same time, I support working-class and working-poor students' efforts to use higher education as a means for improving their material and social circumstances within the existing system. After all, if I hope to teach students to shift from a hierarchical exercise of professional authority to more democratic practices, I must negotiate substantively with them.

As liberal arts education exists now, I can't argue to my family that requiring it is ethically or practically justifiable. It costs working-class people too much materially and psychically to warrant years immersed in a context they often experience as alienating and essentially irrelevant to their life goals and well-being. Still, I believe engaging with historical, literary, and philosophical texts, with the arts and humanistic social sciences, can crucially affect people's lives. In fact, I believe such engagement - if appropriately structured — can ground a revised preparation for professional and civic life.

Such a restructured liberal arts education would encourage both lay and professional participants to negotiate authority by learning to work with discordant representations. After all, professional and civic representations decide questions of how professionals interact with clients, patients, and consumers; of which programs or individuals get funded and which don't; of whether and how a company should bargain with community groups; and of corporate responsibility. Students will likely face such questions in their future careers. An effective liberal arts education would help us use the humanities to address them. Through it, we'd learn how to work with others to recognize and revise the limits of our empathy, to negotiate authority, and to construct the practices of a more democratic professional and civic life.

When I can argue that taking English, philosophy, and history would indeed make Jennifer a better physical therapist in significant ways, ways important both to her goal of a secure job and to lay people's desires for more democratic interactions 
with professionals, I'll be able to respond to my family's challenge. At that point, I'll be prepared to argue that a liberal arts education produces enough public good to justify its substantial psychic and material costs for working-class and working-poor students. For the moment, the imagined ghost of this education spins in the vortex, its promise of a more real democracy glimmering on the edge of embodiment. ${ }^{5}$

\section{Notes}

1. This excerpt from Vincent's Bread, Knowledge, and Freedom: A Study of Nineteenth-Century Working Class Autobiography is used as an epigraph in Carolyn Steedman's Landscape for a Good Woman: A Story of Two Lives.

2. For the trend's impact on the University of Pittsburgh in particular, with emphasis on the shift of support from the humanities core to more lucrative academic units, see Shackner. Articles documenting English academics' concern with the trend abound; see Langland; Armstrong; and Searle. For a more recent evaluation, see Magner.

3. For Habermas's argument on the democratic legacy of the Enlightenment, see The Structural Transformation of the Public Sphere: An Inquiry into a Category of Bourgeois Society. For his theory of language, rational communication, and democratic social practices, see The Theory of Communicative Action, vols. 1 and 2. Iris Marion Young provides one of various important critiques of Habermas's work in 7 ustice and the Politics of Difference.

4. I develop this approach in "Writing Awareness" and in a piece in process, "Frozen Images: The Syntax of Contact, Alienation, and Difference."

5. My sincere thanks to Nancy Atkinson, Ellen Barton, Pamela Batzel, Stephen L. Carr, Angela Farkas, Dennis Gorzelsky, Paul Kameen, Richard Marback, Ruth Ray, and College English's readers for generous, and generative, feedback as I developed this essay.

\section{WORKS Cited}

Armstrong, Paul. "How to Build an English Department in a Time of Retrenchments." ADE Bulletin 115 (Winter 1996): 6-9.

Ball, Arnetha, and Ted Lardner. "Dispositions toward Language: Teacher Constructs of Knowledge and the Ann Arbor Black English Case." College Composition and Communication 48 (1997): 469-85.

Barton, Ellen L. "Literacy in (Inter)Action." College English 59(1997): 408-37.

Ellis, Carolyn, and Arthur P. Bochner, eds. Composing Etbnograpby: Alternative Forms of Qualitative Writing. Ethnographic Alternatives Ser. 1. Walnut Creek, CA: Sage, 1996.

Emanuel, Lynn. The Dig and Hotel Fiesta. Urbana: U of Illinois P, 1995.

Foucault, Michel. The History of Sexuality. Vol. 1. Trans. Robert Hurley. New York: Random, 1990. . "Truth and Power." Power/Knowledge: Selected Interviews and Other Writings, 1972-1977. Ed. Colin Gordon, Leo Marshall, John Mepham, and Kate Soper. New York: Pantheon, 1980. 109-33.

Gorzelsky, Gwen. "Writing Awareness." Journal of the Assembly for Expanded Perspectives on Learning 6 (Winter 2000-2001): 29-39.

Graff, Gerald. Professing Literature: An Institutional History. Chicago: U of Chicago P, 1987.

Graff, Gerald, and Michael Warner. Introduction. The Origins of Literary Studies in America: $A$ Documentary Antbology. Ed. Graff and Warner. New York: Routledge, 1989. 1-14.

Guillory, John. "Preprofessionalism: What Graduate Students Want." Profession 96 (1996): 91-99. 
Habermas, Jürgen. The Structural Transformation of the Public Sphere: An Inquiry into a Category of Bourgeois Society. Trans. Thomas Burger and Frederick Lawrence. Cambridge: MIT P, 1993.

- The Theory of Communicative Action. Vols. 1 and 2. Trans. Thomas McCarthy. Boston: Beacon, 1984 and 1987.

Kameen, Paul. Writing/Teaching. Pittsburgh Series in Composition, Literacy, and Culture. Pittsburgh: U of Pittsburgh P, 2000.

Kolker, Aliza. "Thrown Overboard: The Human Costs of Health Care Rationing." Ellis and Bochner 132-59.

Langland, Elizabeth. "Holding the Line: The Idea of the Faculty in an Age of Downsizing." ADE Bulletin 115 (Winter 1996): 14-19.

Linden, R. Ruth. "The Life Boat Is Fraught: Reflections on 'Thrown Overboard.” Ellis and Bochner $160-71$.

Lu, Min-Zhan, and Bruce Horner. "The Problematics of Experience: Redefining Critical Work in Ethnography and Pedagogy." College English 60 (1998): 257-77.

Magner, Denise K. "For Job Hunters in Academe, 1999 Offers Signs of an Upturn." Chronicle of Higher Education 29 Jan. 1999: A14+.

Perls, Frederick, Ralph E. Hefferline, and Paul Goodman. Gestalt Therapy: Excitement and Growth in the Human Personality. New York: Dell, 1951.

Rodriguez, Richard. Hunger of Memory: The Education of Richard Rodriguez. New York: Bantam, 1982.

Rose, Mike. Lives on the Boundary. New York: Penguin, 1989.

Said, Edward W. Orientalism. New York: Pantheon, 1978.

Searle, Leroy F. "Institutions and Intellectuals: A Modest Proposal." Profession 96 (1996): 15-25.

Shackner, Bill. "Pitt Reshuffles Academic Deck." Pittsburgh Post Gazette 3 April 1997: A1+.

Shor, Ira. Empowering Education: Critical Teaching for Social Change. Chicago: U of Chicago P, 1992.

Shumway, David R. “The Star System in Literary Studies.” PMLA 112 (1997): 85-100.

Spellmeyer, Kurt. Common Ground: Dialogue, Understanding, and the Teaching of Composition. Englewood Cliffs, NJ: Prentice Hall, 1993.

Spivak, Gayatri Chakravorty. "Can the Subaltern Speak?" Marxism and the Interpretation of Culture. Urbana: U of Illinois P, 1988. 271-313.

- Outside in the Teaching Machine. New York: Routledge, 1993.

Steedman, Carolyn. Landscape for a Good Woman: A Story of Two Lives. London: Virago, 1986.

Vincent, David. Bread, Knowledge, and Freedom: A Study of Nineteenth-Century Working Class Autobiography. London: Europa, 1981.

Young, Iris Marion. Fustice and the Politics of Difference. Princeton: Princeton UP, 1990.

Zinker, Joseph C. In Search of Good Form: Gestalt Therapy with Couples and Families. San Francisco: JosseyBass, 1994. 